\title{
EL MONUMENTO DE MEZORA (CHOUAHED, ARCILA, MARRUECOS). DATOS INÉDITOS SOBRE LAS EXCAVACIONES ${ }^{1}$
}

\author{
Enrique Gozalbes Cravioto \\ Universidad de Castilla-La Mancha \\ (In memóriam)
}

\begin{abstract}
Resumen: Hasta el momento se han mantenido muchas incógnitas sobre el proceso de excavación arqueológica realizado entre 1934 y 1936 en el monumento de Mezora en el Marruecos Atlántico. La falta de informes oficiales obligaba a los investigadores a realizar aproximaciones, más o menos lógicas o documentadas, acerca de los resultados. La puesta a disposición del investigador de una serie de informes realizados por el arqueólogo, que se mantienen en el Archivo familiar, junto con numerosas fotografías del momento, permite un avance en los conocimientos. El mismo se realiza a partir de la reinterpretación actualizada de lo percibido en su momento por el arqueólogo, así como con comprobaciones que derivan de las fotografías de la excavación. A partir de ahí parece deducirse la existencia en el lugar de un primer momento representado por un espacio ritual, rápidamente reconvertido con una gran obra en una tumba de aspecto exterior monumental.
\end{abstract}

Palabras Clave: arqueología, protohistoria, monumento funerario, historiografía, protectorado español.

Abstract: So far there have been many unknowns about the process of archaeological excavation carried out between 1934 and 1936 in the monument of Mezora in the Atlantic Morocco. The lack of official reports forced researchers to make more or less logical or documented approximations of the results. The availability of the researcher of a series of reports made by the archaeologist, which are kept in the Family Archive, along with numerous photographs of the moment, allows us to move along in the knowledge. This advance got from the updated reinterpretation of what was perceived at the time by the archaeologist, as well as with checks that derive from the photographs of the excavation. From this it seems to be deduced the existence in the place of a ritual space, quickly reconverted with a great work in a tomb of monumental exterior aspect.

Keywords: Archeology, Protohistory, funerary monument, historiography, Spanish protectorate. 


\section{Presentación}

El monumento megalítico de Mezora (M'Zora) se encuentra ubicado en el Noroeste de Marruecos en la comuna del Tnin de Sidi Lyamani, a una quincena de kms. en línea recta al Sudeste de la población de Arcila (Asilah). Este monumento constituye una de las construcciones más relevantes de la prehistoria-protohistoria de este país. La bibliografía sobre este monumento megalítico es particularmente numerosa, si bien la mayor parte de la misma es meramente descriptiva (Souville, 1973, 32-35). Ya en el siglo XIX algunos viajeros y diplomáticos europeos se interesaron por este lugar, al que compararon con Stonehenge, pero la primera aproximación realmente científica sólo se produjo en la primera mitad del siglo XX (Koehler, 1932).

Después de la limpieza y de la excavación, de la que trataremos en el presente trabajo, el monumento de Mezora fue estudiado en la publicación clásica efecruada por parte de Miguel Tarradell Mateu, que ha servido de referente hasta la actualidad (Tarradell, 1952). Como elementos novedosos posteriores debe de mencionarse el intento de aplicación al mismo de la arqueoastronomía (Mavor, 1976), la observación sobre hipotéticas nuevas estructuras (Souville, 2000), y más recientemente la revisión de los datos conocidos, con la incorporación de novedades a partir de las fotografías antiguas, informaciones orales y estudios realizados sobre el propio terreno (Gozalbes, 2006; Gozalbes, 2012a).

La descripción del conjunto arqueológico refleja con claridad el carácter en algunos puntos hasta espectacular que debió de tener en el momento de su construcción. El conjunto consiste en un gran círculo que estaba compuesto en un origen por unos 176 megalitos de unas alturas bastante diferentes, pero generalmente de unos $60-80 \mathrm{cms}$ de altura sobre el suelo. En muchas zonas de su recorrido por el interior del círculo hay desplegado un enlosado relativamente muy bien hecho, de piedras cortadas y bien alisadas que aumentan la monumentalidad. En el centro de dicho círculo de monolitos, ocupando la mayor parte de éste, se erigió

El presente trabajo se ha desarrollado parcialmente en el marco de nuestra participación en el Proyecto de I+D+i MINECO-Ministerio de Economía y Competitividad, ref. HAR2012-334033 (vigencia 2013-2016), y actualmente (desde 2017) en el I+$D+i$ : Arqueología e interdisciplinariedad: una investigación arqueológico-histórica sobre las relaciones interdisciplinares en la Historia de la Arqueología española (siglos XIX y XX). HAR2016-80271-P. El estudio realizado de los documentos del Archivo del Museo Arqueológico de Tetuán se ha realizado con la autorización correspondiente del Ministerio de Cultura del Reino de Marruecos, concedida en 2013, por parte de la Dirección del Patrimonio Cultural. 
un enorme túmulo de tierra y piedras acumuladas de unos 6 metros de altura en la cúspide. En algunos puntos de este túmulo se detecta la construcción de un murete de contención de la tierra, con la utilización de piedras cortadas, y en algún caso con la disposición de un aparejo de un carácter claramente helenístico.

En su entorno hay también restos de otros conjuntos de megalitos, en los que de una forma teórica pero nada segura en todos los casos, se apunta una disposición igualmente en círculo. Como se ha destacado en muchas ocasiones en la comparativa con otros mausoleos antiguos del Magreb, Mezora es el de unas mayores dimensiones y constituye un monumento único en su género en todo Marruecos (Souville, 1965; Souville, 1968). Este hecho justifica ese enorme interés que ha despertado y que explica la extensa bibliografía existente. [1]

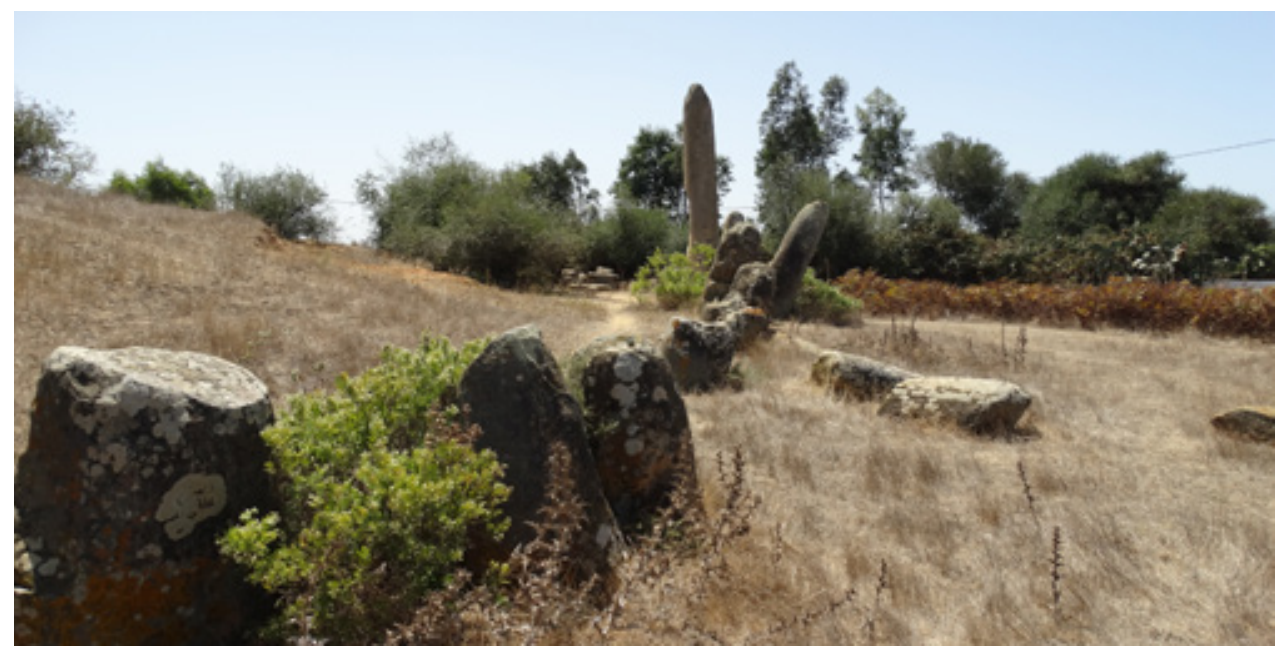

Fig.1. Vista parcial del estado actual del círculo megalítico de Mezora.

El monumento de Mezora fue excavado en los años treinta por parte de César Luis Montalbán Mazas, quien era en aquella época Director del Museo Arqueológico de Tetuán y Jefe de las Excavaciones del Protectorado español en Marruecos adscrito a la Junta Superior de Monumentos Históricos de Marruecos. El personaje, olvidado y bastante desconocido hasta hace bien poco tiempo, sin embargo en la última década está siendo objeto de atención en sus aportaciones por parte de la historiografía (Gozalbes, 2012). Después de realizar excavaciones en los conjuntos arqueológicos de Tamuda y de Lixus, y de organizar por vez primera en 1926 el Museo Arqueológico de Tetuán, bajo la Segunda República plan- 
teó desarrollar un proyecto por el que pugnó otro estudioso, como hemos publicado recientemente, en concreto el periodista de origen italiano Angelo Ghirelli (Gozalbes, 2018).

Hasta el momento hemos carecido de una documentación mínimamente adecuada acerca de la excavación realizada en Mezora por parte de César Luis Montalbán, que por otra parte ha sido muy criticada por parte de no pocos investigadores, debido al desconocimiento de la existencia de informes que hubieran sido elaborados por el propio arqueólogo. Sin embargo debemos indicar que en fechas muy recientes los descendientes del Sr. Montalbán han tenido la loable iniciativa de poner a disposición de los investigadores toda una serie de textos y de fotografías pertenecientes al archivo personal del explorador y arqueólogo. La medida ha sido muy de agradecer, al menos lo es por nuestra parte, puesto que aquí hemos podido

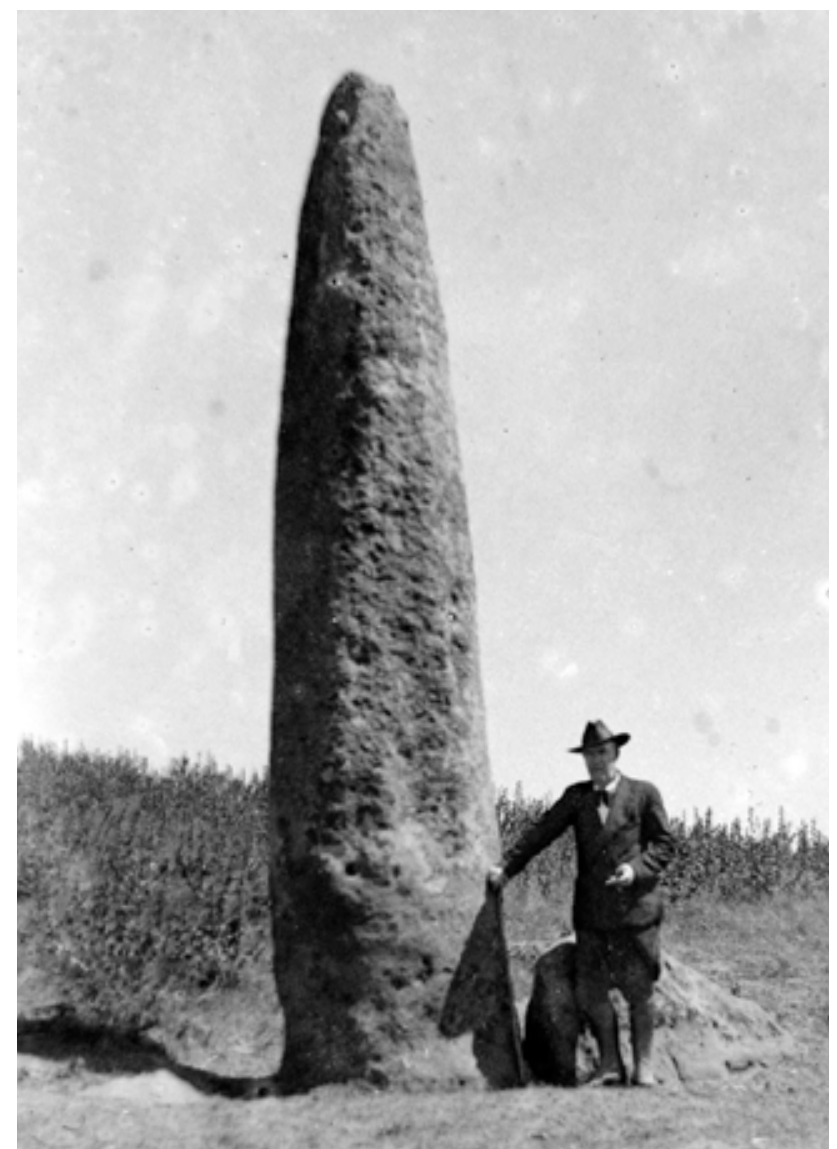

Fig.2. César Luis Montalbán junto a El-Outed, el monolito mayor del monumento de Mezora detectar la existencia de una documentación que consideramos que es particularmente relevante acerca del monumento megalítico de Mezora y que desde hace muchísimos años se consideraba como una información irremisiblemente perdida para el debido conocimiento científico. Estos textos y fotografías antiguas consideramos que merecen nuestro análisis detallado y justifican el presente trabajo debido a los numerosos datos que aportan, aunque naturalmente la información de Montalbán y sus opiniones deban ser manejadas con la lógica prudencia de la antigüedad de la misma y de las interpretaciones personales de todo estudioso de aquella época. [2] 


\section{Sobre el monumento de Mezora}

El monumento de Mezora se trata de un sitio arqueológico a cuyo estudio nosotros hemos dedicado algunos trabajos, y acerca del que venimos investigando desde hace prácticamente cuatro décadas. Siempre los investigadores, que como señalamos además han sido particularmente numerosos, que hemos tratado acerca del mismo nos hemos lamentado invariablemente de dos hechos que en sí mismos han dificultado, de forma aparentemente insalvable, el avance de los conocimientos acerca de un monumento que ha sufrido un proceso de deterioro:

- Por un lado, la ausencia de una documentación concreta, no digamos que de contenido estrictamente técnico o científico, acerca del proceso de excavaciones que fueron realizadas en los años treinta, y por supuesto en relación con sus resultados; destacamos por ejemplo las consideraciones formuladas en su día por parte de Georges Souville: "il a été fouillé en 1935 et 1936 par L. de Montalban qui n'a malheureusement laissé aucun document" (Souville, 2000: 490). La inexistencia de estos informes es precisamente uno de los motivos principales de crítica a la labor realizada por parte del mencionado arqueólogo.

- Por otra parte, también ha sido general la constatación del fuerte deterioro sufrido por el monumento, y que ya en escritos de los años cuarenta y cincuenta del siglo pasado se atribuía directamente a la actuación del arqueólogo que llevó a cabo la intervención arqueológica Así pues, habría sido la especial impericia la que habría provocado estos resultados.

Es cierto que en nuestros trabajos más recientes hemos planteado y matizado fuertemente estas consideraciones tan contundentes, al integrar algunos datos que apuntaban, al menos parcialmente, en otras direcciones. En este sentido las matizaciones y rectificaciones, o cuando menos explicaciones, se han centrado sobre todo en la toma en consideración del contexto, es decir, de la situación más o menos peculiar de aquel momento, en relación con lo que se ha escrito corrientemente y que además apareció en la bibliografía ya desde muy primera hora. En este sentido parece claro que, más allá de otras consideraciones que legítimamente puedan hacerse, y reparos de actuación en legítima crítica científica, César L. Montalbán sufrió un proceso de damnatio memoriae, inicialmente consciente debido a su persecución por el franquismo, y después probablemente más inconsciente debido a los frustrantes resultados arqueológicos de la intervención en Mezora.

En este sentido, es enteramente cierto que César Luis Montalbán no publicó absolutamente nada acerca de los resultados obtenidos en su 
intervención arqueológica, un hecho que además era muy característico en él, pero no lo es menos que sí dio privadamente algunos informes orales que fueron más o menos limitados según cada caso (especialmente y de forma próxima en el tiempo a Pelayo Quintero y a Julio Martínez SantaOlalla) los cuales, junto con el testimonio de alguno de los trabajadores participantes o familiares de los mismos, y con documentos del Archivo del Museo Arqueológico de Tetuán, nos han servido para tener algunos datos que nos parecen especialmente relevantes. Sin duda el principal de todos esos datos tenidos en cuenta ha sido el de la aparición en el interior de la colina artificial de una tumba, probablemente de cremación, constituida por una caja o cista de lajas de piedras bien cortadas y con el hallazgo de una especie de cuchillo metálico en su interior (Daugas, El Idrissi, Daugas, Chevet y Ouchou, 2003). Esta referencia, sin embargo, queda algo oscurecida, como veremos más adelante, en los informes escritos del propio César L. Montalbán.

La segunda línea de revisión que incorporamos en nuestros trabajos, fue realizada sobre todo también a partir de la utilización que hicimos de las fotografías aéreas de la época, especialmente realizadas por el Servicio del Ejército español. En la revisión de esas fotografías, realizadas entre los años 1934 y 1936, concluíamos que se debían distinguir dos etapas diferentes en el proceso arqueológico desarrollado por C. L. Montalbán en Mezora. La primera de ellas fue la limpieza del círculo megalítico, que fue muy efectiva y a la que a nuestro juicio difícilmente pueden ponerse unas objeciones realmente serias, quizás simplemente la realización de algunos movimientos de los monolitos derribados que fueron desplazados probablemente con simples criterios de presentación del monumento (que fue visitado por el Jalifa de la zona Cherifiana unos meses antes del estallido de la Guerra Civil). En ese trabajo de limpieza realizado por Montalbán quedó bien a las claras la estructura real que tenía el círculo exterior, así como por vez primera la existencia del número de monolitos que era bastante superior al que previamente se suponía. [3]

La segunda fase del trabajo arqueológico desarrollado en Mezora, la de la excavación del interior del túmulo, siguió los moldes que pueden considerarse más o menos erróneos pero que por otra parte debe reconocerse que eran totalmente usuales en la época. Se trató de una potentísima intervención de extracción de las tierras a partir de una interpretación que estaba derivada de la communis opinio (incluida la muy autorizada en esos momentos como era la del profesor $\mathrm{H}$. Obermaier, que era profesor de la Universidad de Madrid) de que se trataba de un sepulcro de corredor, como lo eran los especialmente potentes existentes en el Sur de España 


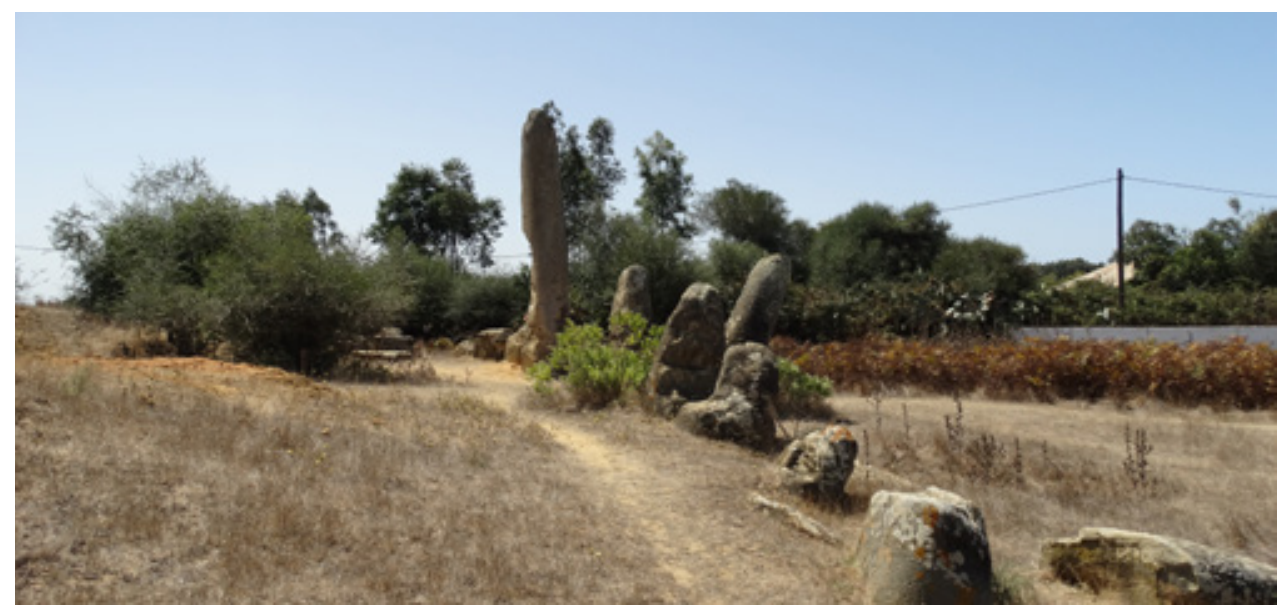

Fig.3 Círculo de Mezora. Estado actual. Zona de El Outed o monolito principal.

estudiados por el especialista mencionado. No es casualidad que en esa misma época, para su exposición en el Museo Arqueológico de Tetuán, no sólo se realizara una maqueta del monumento antes de proceder a su excavación, maqueta que todavía en la actualidad se encuentra en la sala de prehistoria del mismo, sino también de otros monumentos megalíticos hispanos tales como el dolmen de Soto, en la provincia de Huelva, o de una naveta y de un talayot de la isla de Menorca. En este sentido, inicialmente Montalbán buscó un corredor en la colina porque era lo normal y esperable por todos que tuviera la tumba, pero se encontró con otras realidades diferentes. A partir de ahí, se detecta que este monumento era particularmente complejo, de forma que en realidad escapaba de las potencialidades de estudio en ese momento.

En realidad debe indicarse que el deterioro padecido por el emblemático monumento megalítico marroquí, más allá de la propia y agresiva intervención que era relativamente explicable en la época, se debió mucho más a las abruptas y dramáticas circunstancias del final de los trabajos sobre el terreno, con la detención de Montalbán a punta de fusil en el campo arqueológico por parte de las tropas sublevadas al inicio de la Guerra Civil española en julio de 1936, así como el abandono de cualquier protección del lugar y el saqueo posterior de los restos por parte de gentes de la región que arramblaron con todos los enseres y también con los principales materiales que desaparecieron a continuación. A partir de ese dramático punto, se produjo el abandono absoluto del monumento, su deterioro prácticamente constante, nosotros mismos pudimos detectar hacia 1980 la extracción ilegal de tierra, y poco antes de ese momento in- 
cluso una intervención "arqueológica" irregular, entre otras muchas que sin duda las propias evidencias han ido señalando a lo largo de los años. Una situación que no derivada directamente de la excavación en sí y, por tanto, absolutamente ajena a la responsabilidad del arqueólogo.

Pese a lo indicado, no todo ha sido negativo últimamente aunque lo parezca. Por ejemplo, la existencia del proyecto de construcción de una autovía que pasaba justo por el monumento terminó a partir de la decidida intervención entonces de las autoridades de patrimonio, en especial del profesor Mehdi Zouak, con el traslado del trazado para preservar el monumento. Igualmente hace unos pocos años se ha dotado al recinto más cercano de una valla protectora que sin duda limita mucho las agresiones (entre otras cosas, las producidas con punzones en algunos monolitos incluido el principal de ellos que tiene 6 metros de altura). Ello sin duda salva de muchos de los peligros de una definitiva destrucción del "Stonehenge marroquí". Aún y así, es cierto que continúan existiendo algunas actividades irregulares en el entorno y además bien visibles: en una visita realizada en 2015 pudimos observar a unos 120 metros del monumento, a poca distancia del considerado conjunto secundario $\mathrm{A}$, y fuera del recinto protegido del círculo megalítico, una actividad de movimiento desordenado de la tierra con aparición en el subsuelo de restos de al menos dos pequeños monolitos (o fragmentos de los mismos) que eran hasta el momento bien desconocidos.

\section{Los datos sobre Mezora}

Volviendo a la actividad del arqueólogo, en el año 1939 C. L. Montalbán, tras su paso por la prisión militar de El Hacho en Ceuta, y a la espera de resolver su expediente de depuración política, fue repuesto provisionalmente, simplemente en funciones, en la dirección del Museo Arqueológico de Tetuán mediante los oficios del Secretario General de la Alta Comisaría, Tomás García Figueras. En el Museo de Tetuán Montalbán recibió en el verano de ese año a Julio Martínez Santa-Olalla, que sería a partir de esos momentos el jefe de la arqueología española (Comisaría General de Excavaciones) y quien pretendía extender sus influencias y control arqueológico al Protectorado marroquí (Gozalbes, 2015). Y sobre todo, fue a quien Montalbán informó y pasó algunas fotografías de la excavación realizada en el monumento de Mezora; tiempo más tarde, Martínez Santa-Olalla presumiría de haber realizado sobre el terreno mismo un estudio, "por vez primera completo" del monumento, en realidad disponiendo de los datos que le fueron aportados por Montalbán, pero que nunca publicó y probablemente ni siquiera comenzara realmente a redac- 
tar (Martínez Santa-Olalla, 1945; Martínez Santa-Olalla, 1948).

En la documentación existente en el Archivo del Museo Arqueológico de Tetuán no hay memoria alguna sobre las excavaciones de Mezora de los años treinta, pero es cierto que sí un documento mecanografiado, en un simple texto, en el que con la firma del propio Montalbán y la fecha casi segura de septiembre de 1939 se planteaban los "Trabajos necesarios para la conservación del cromlech de Mezora, para su conservación durante el año 1940". En el mismo se alude a los grandes desperfectos realizados en los "trilitos y taulas", los menhires derribados en ese tiempo (indudablemente a posta), "construir las dos puertas que destrozaron y la parte de las cercas y alambradas que han destruido", sin duda alguna se refiere a los saqueadores ya mencionados (fig. 2). Este documento prueba el fortísimo impacto del expolio sufrido por el monumento en el verano de 1936, unas circunstancias hasta ahora no tenidas en cuenta por parte de la historiografía, pero que a nuestro juicio son imprescindibles de ser tenidas en cuenta. [4]

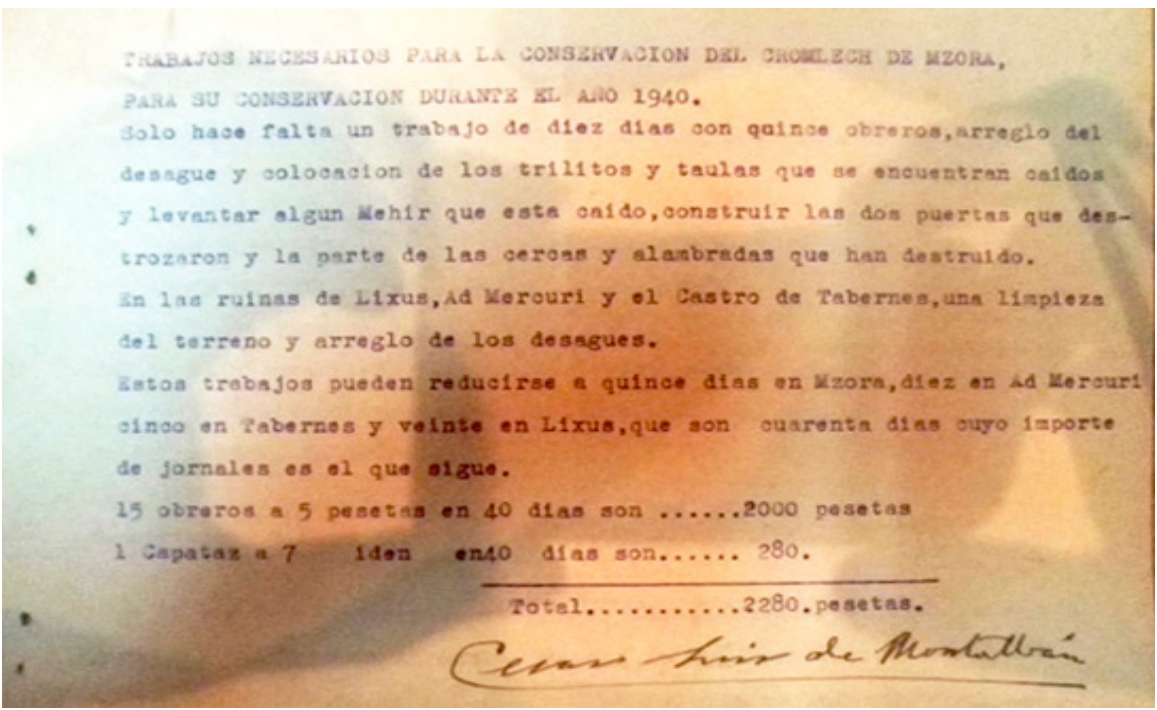

Fig.4. Documento de 1939 de Montalbán en relación a trabajos de protección en Mezora.

Justamente después de esos precisos momentos, C. L. Montalbán sería sustituido en la dirección del Museo por parte de Pelayo Quintero Atauri, profesor jubilado y anterior Director del Museo de Cádiz. Sobre la labor arqueológica de Pelayo Quintero, Director hasta su fallecimiento en 1946 del Museo Arqueológico de Tetuán, en los últimos años se han multiplicado también los trabajos (Parodi y Gozalbes, 2011, así como la Tesis 
Doctoral de Parodi, 2017). De forma aparentemente inesperada para él, Montalbán quedó desplazado a Larache al desempeño de actividades de colaboración patrimonial y arqueológica en espera del pleno cumplimiento de su expediente político por parte del régimen franquista. Conocemos también al menos parcialmente su amarga correspondencia con las autoridades del Protectorado, desarrollada a partir de reproches de reproducción innecesaria.

En el año 1945, repuesta la internacionalidad de la ciudad de Tánger después de la temporal ocupación española durante la Segunda Guerra Mundial, César L. Montalbán pasó como refugiado a la misma donde tiempo más tarde recibiría el encargo de estudio y preservación del patrimonio tangerino por parte de la administración internacional. Nunca publicó nada al respecto del monumento, si bien dispuso como era de prever, de informes en su Archivo personal en la ciudad tangerina, en la que fallecería en el año 1971. Puede resultar plenamente comprensible el que en estas dramáticas circunstancias Montalbán no elaborara escrito alguno sobre Mezora, pero lo más extraño es que no lo hubiera hecho precisamente antes de ese desgraciado julio de 1936: como indicamos, en el Archivo del Museo de Tetuán no se conserva memoria alguna al respecto que, por otra parte, hubiera sido preceptiva en el marco de la institución patrimonial encargada de la arqueología como era la Junta Superior de Monumentos Históricos de Marruecos, creada en 1919.

\section{La documentación del Archivo Montalbán}

En fechas muy recientes la familia de Montalbán, en concreto su nieta, ha iniciado un proceso de dar a conocer las actividades del explorador y arqueólogo tan injustamente olvidadas o mal interpretadas. Para ello ha puesto a disposición del estudio de F. J. Pérez Escribano la labor de análisis del archivo Montalbán, que este investigador ha iniciado con una visión general acerca de las actividades arqueológicas, con la consulta sobre todo de textos y documentos de los años veinte y treinta. Esta documentación suele consistir en Memorias mecanografiadas, copias de ellas, y un abundante aparato fotográfico, de las que normalmente eran remitidas a la Junta Superior de Monumentos Históricos de Marruecos (bajo la República a partir de 1931 cambió el título de "Superior" por "Central") por ser ésta la encargada del Patrimonio en el Protectorado español, y precisamente la que abonaba el salario de Montalbán (primero como Asesor Técnico y después como Jefe de Excavaciones).

Los documentos de este tipo, en copias conservadas en otras bibliotecas y archivos, ya fueron estudiados por nosotros hace algu- 
nos años y de ellos extrajimos precisamente muchos de los datos dados a conocer en la interpretación del trabajo arqueológico desarrollado por parte del mencionado (Gozalbes, 2008; Gozalbes, 2012). Sin embargo, como hace años ya destacamos a la propia nieta del Sr. Montalbán, había dos elementos particularmente que resultaban desconocidos por parte de todos y cuya aportación documental sería particularmente relevante para el avance de conocimientos por parte de los investigadores: el primero de ellos se refería a todo lo referido a la excavación de Mezora, y el segundo, a su desconocida actividad en la arqueología tangerina entre 1946 y 1957. Una primera aproximación al respecto ya formulamos en un trabajo anterior (Gozalbes, 2017).

En el último año la nieta del Sr. Montalbán ha colgado en una red social (Facebook) toda una serie de documentos y fotografías de importancia particularmente sensible para el estudio del monumento de Mezora. Con su correspondiente autorización expresa, y a quien mostramos el mayor de los agradecimientos por su aportación que es especialmente importante, la vamos a utilizar para presentar algunas novedades que consideramos que sí son particularmente relevantes sobre Mezora. Una buena parte de las fotografías se encuentran reunidas en el archivo de Montalbán en un documento titulado (muy al estilo del autor) "Gráficos para el estudio del cromlech de M'Zora", que lleva la fecha de 1936. Entre las fotografías aportadas hay alguna aérea realizada en esos momentos de la excavación (fig. 3). En ella se puede observar la existencia de la primera zanja trazada desde el monolito principal, en medio de la cual aparece un muro de piedras acumuladas, así como la apertura sin terminar de la segunda zanja transversal. [5]

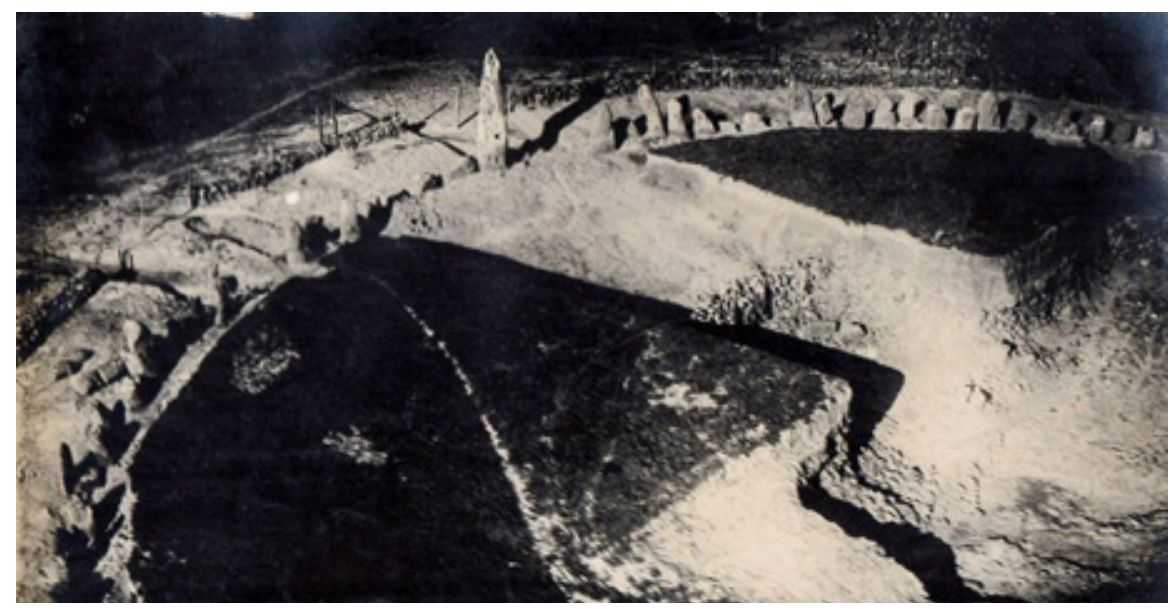

Fig.5. Foto aérea de las excavaciones en 1936. 
La puesta a disposición de los investigadores e interesados de esta documentación supone, sin duda, cumplir el loable objetivo de su familia, como es el de dejar ante la vista la realidad más objetiva, mediante una reivindicación, de la labor realizada por C. L. Montalbán, pero sobre todo el poner a disposición de los investigadores unas informaciones que resultan realmente más preciosas que en ocasiones precisas como después veremos: debe entenderse la diferencia entre los informes arqueológicos actuales y los escritos de aquella época. Pero el testimonio escrito del arqueólogo, que es el propio del trabajo y de las percepciones de la época, naturalmente necesitan de una correspondiente re-interpretación a la luz de lo que sabemos (o pretendemos saber) muchísimas décadas más adelante. Nuestra reinterpretación de las percepciones de aquel momento en absoluto resulta definitiva, alguna de las consideraciones de Montalbán, incluso no encaja con algún aspecto relevante formulado por nosotros mismos, aunque es cierto que en muchas cuestiones vienen a confirmar en general la visión que sobre el monumento hemos defendido en diversas ocasiones.

\section{El primer informe}

El primer informe que nos interesa no lleva una fecha concreta, pero la misma se deduce precisamente a partir del segundo de los escritos en el que se hace referencia a la presentación a la Junta Superior de Monumentos Históricos de Marruecos en marzo de 1934 del proyecto de realización de los trabajos. Este proyecto aludido es por tanto de fecha marzo de 1934 y lleva por título "Los monumentos megalíticos de M'Zora". En buena parte del informe lo que hace realmente C. L. Montalbán es explicar el significado que en esos momentos se suponía que tenían los monumentos megalíticos y planteaba la necesidad de realizar la investigación en uno de la importancia del de Mezora precisamente en el Protectorado español. En este sentido, la dirección principal se dirigía a concienciar de esa relevancia de un tema a la que podían perfectamente ser ajenas las autoridades.

Nos parece especialmente relevante el que en el informe se plantea directamente la consultoría especializada que debería seguirse del profesor Hugo Obermaier, quien había visitado y prospectado en la prehistoria del Marruecos español, y quien mantenía unas buenas relaciones con Montalbán, lo cual obviamente le iba a servir para potenciar su posición a partir de una autoridad internacional, de hecho la máxima en prehistoria existente en esos momentos en España. Entonces también lanza lo que sin duda era un aspecto de un sensible atractivo político para el prestigio del Protectorado español: "pueden dar a la Junta Central de Monumentos mucha más importancia de la que tiene en el mundo arqueológico que 
constantemente se le piden noticias de la labor que realiza". Alude sin duda fundamentalmente al interés que en los años treinta L. Chatelain primero, y R. Thouvenot y J. Carcopino después, mostraron por los restos arqueológicos del Protectorado. En este sentido, C. L. Montalbán proponía que la exploración de Mezora fuera por él desarrollada entre los meses de agosto, septiembre y octubre de ese mismo año. Ese interés político terminará por fraguar con la visita a Mezora ya mencionada, unos meses antes del estallido de la Guerra Civil, del Jalifa Muley el-Mehdi. [6]

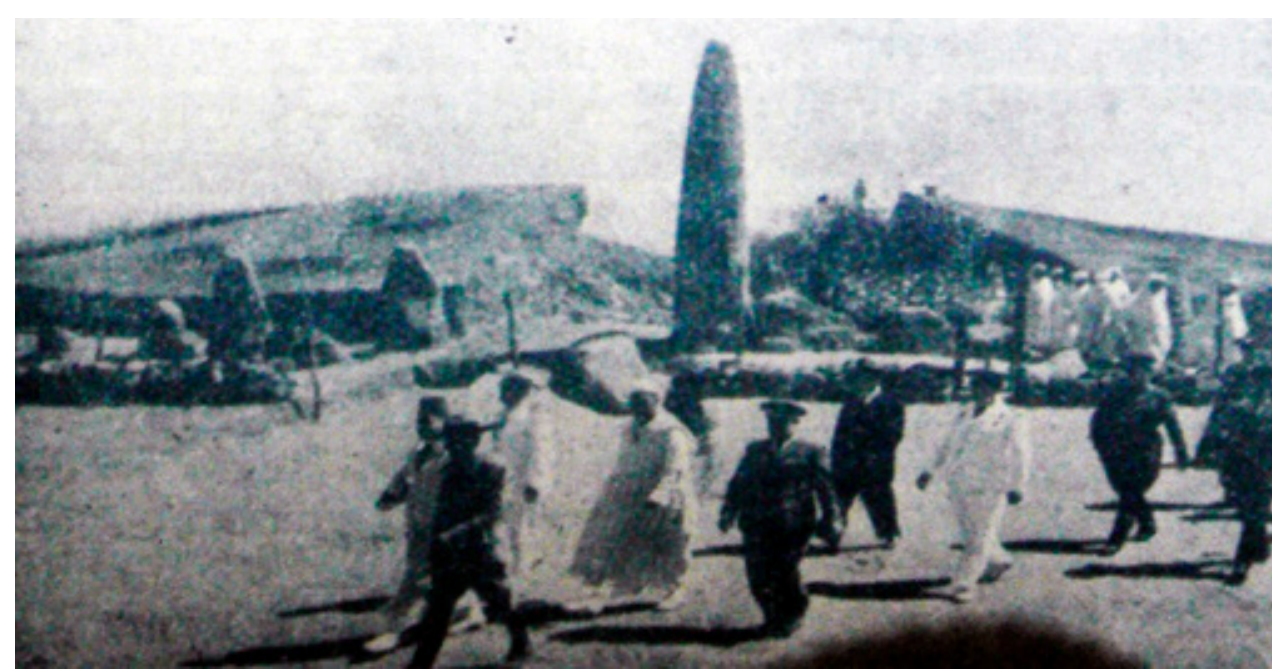

Fig.6. Visita a Mezora del falifa Muley el-Mehdi

\section{E1 segundo informe sobre Mezora}

El segundo documento que nos interesa está firmado por Montalbán en Larache el 25 de abril de 1935. En el mismo parece claro que todavía no había accedido a excavar en el interior del túmulo. Este informe, aparentemente sin título, hace referencia a la presentación por su parte a la Junta Superior de Monumentos el 6 de marzo de 1934 del proyecto de realización de los trabajos, que es precisamente el texto anterior. La intervención arqueológica, la limpieza del círculo de megalitos, se efectuó entre los meses de septiembre y de noviembre de 1934 (por tanto en el tiempo pero con retraso de un mes sobre lo planteado antes). Tenemos por consiguiente aquí ya precisada la fecha de los primeros trabajos realizados por Montalbán en Mezora. Buena parte de este informe está destinado a recoger nuevamente unas consideraciones de carácter general sobre los crómlech europeos, entendidos de unas formas diferentes, en especial como 
templos solares, si bien Montalbán se quejaba con cierta sentimiento de no poder lograr una orientación adecuada acerca de su carácter: "por la diversidad de opiniones expuestas se sufre un notable perjuicio en el estudioso.... pues la pasión y el amor propio crean la confusión en los diversos estudios".

Dos aspectos merecen sin embargo la atención de una forma especial en este segundo informe. Por un lado, el que se refiere a la aparición a lo largo de los trabajos de un numerosísimo instrumental lítico, que sin duda fue de distintas características, pero que Montalbán deduce que marcaban en buena parte una similitud con el "Musteriense Ibero-Mauritánico" descubierto por J. Pérez de Barradas en Madrid, si bien las piezas "encontradas por nosotros son de mejor factura y de más importancia". Este hecho, junto con la consideración de que se hallaba especialmente "en la capa superior del cromlech, plantea el problema de su cronología o adscripción; a nuestro juicio la primera consideración apunta obviamente a un neto predominio de utillaje de factura eminentemente paleolítica, pero la consideración de "mejor factura" apunta a una más cuidada talla de ese supuesto Musteriense, lo que parece señalar más o menos obviamente al Ateriense (Paleolítico Superior norteafricano).

Este hecho no tiene nada de extraño, pues la mencionada industria tiene una fuerte presencia en toda la zona del entorno del monumento tal y como nosotros mismos hemos podido detectar, en concreto con un taller de fabricación de utillaje del Ateriense y del Iberomauritano al Norte del monumento, y además está bien representada en el material de Mezora en el Museo de Tetuán. Es igualmente poco dudoso que, además la referencia a la "capa superior", lo que encierra es la realidad de que este numerosísimo instrumental lítico, como hoy aunque mucho más expurgado ya a estas alturas, se hallaba profusamente entre la tierra de los alrededores y que los constructores de Mezora acumularon para la fabricación del círculo y sobre todo de la colina central. Así pues, el planteamiento de Montalbán de aplicar una especie de "estratigrafía" era simplemente absurdo. Aún y así, por simple recogida de material, habría sido relevante la conservación de aquel recuperado por Montalbán, en la medida en la que se hallarían 'piezas de industrias diferentes, incluidas algunas de etapas más cercanas a la erección del monumento.

El segundo aspecto relevante que nos interesa en este segundo informe es la alusión que realiza a los grabados existentes en los monolitos. La memoria de la existencia de los mismos, planteada por Copell de Brooke en 1831, y luego en parte sólo detectada un siglo más tarde por parte de A. Ghirelli en 1932, se ha perdido hasta que nosotros mismos 
recientemente la hemos devuelto con nuestro estudio y la localización de los principales de esos grabados que están presentes en los monolitos (Gozalbes y Gozalbes-García, 2015), e incluso con la localización del punto en el que Arthur Copell de Brooke identificó la existencia de una entrada (la considerada como secundaria respecto al monolito principal) del círculo (fig. 6). Aunque lo que Montalbán recoge sobre la bibliografía anterior, en un cierto alarde científico realizado ante la Junta Superior de Monumentos, en realidad está tomado indirectamente de un trabajo de A. Blázquez y Delgado-Aguilera de 1917, puesto que reproduce exactamente sus mismos errores de interpretación de un texto francés, sin embargo conoce la aportación formulada por el periodista y aficionado a la arqueología Angelo Ghirelli pero de una forma muy decidida entra en una polémica muy directa con el periodista italiano que había pugnado por encargarse del proyecto arqueológico de Mezora (Gozalbes, 2018). [7]

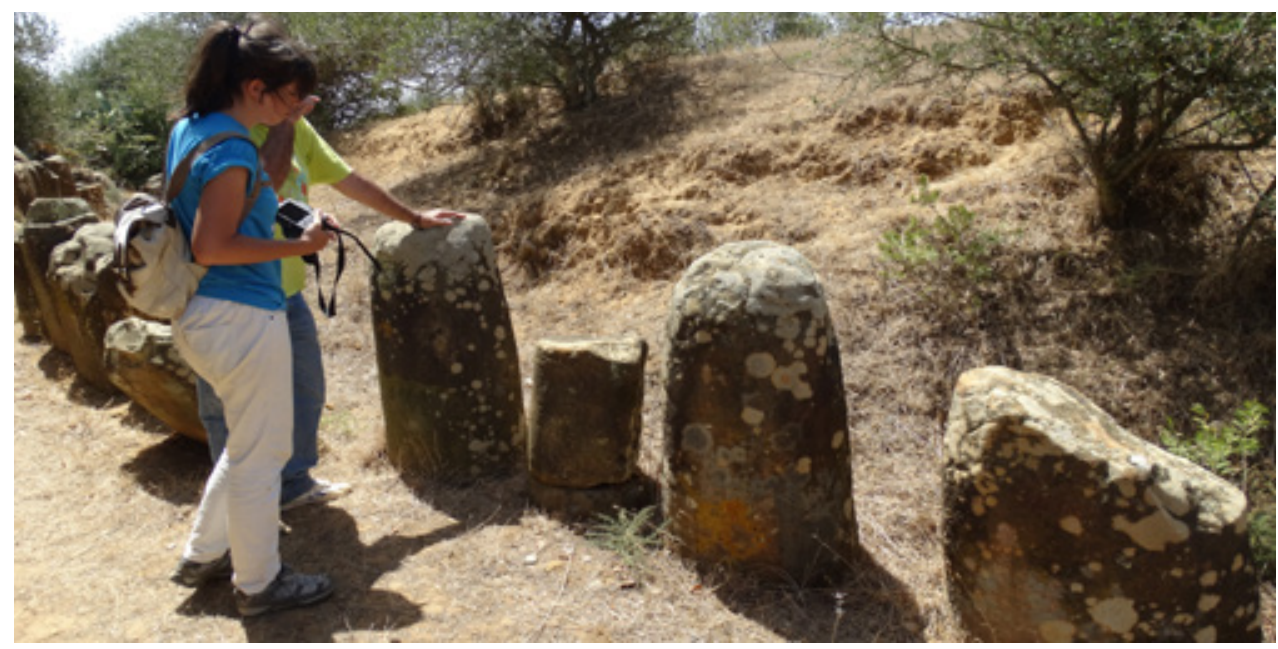

Fig.7. Momento de la localización de la puerta secundaria en el círculo de la que habló Copell Brooke en 1831. El monolito intermedio partido está desplazado en medio de la entrada.

De lo aquí escrito se deduce claramente que existía una fortísima tensión entre ambos personajes que, por otras fuentes, conocemos incluso trasladada a las escasas ocasiones en las que entraron en contacto personal. Montalbán en su informe reprochaba que dichos grabados no se encontraban precisamente en el lugar exactamente señalado por Angelo Ghirelli, en lo que (al menos a nuestro juicio) realmente constituía un problema simple de valoración de los puntos cardinales y de las tomas de referencia (que eran ciertamente erróneas en A. Ghirelli como señalamos en nuestro trabajo anterior), y por eso propone "se levante acta de la situación de dichos menhires y calco de los mismos". El tenor de lo expresado muestra la 
profunda desconfianza ante los posibles ataques a recibir de un enemigo que podrían servir para desprestigiar el trabajo realizado.

Se trataba de una opción que era muy loable si bien la interpretación señalaba la existencia de esa tensión larvada entre los dos arqueólogos: "de no hacerlo así, se podría tachar en el futuro a la Junta o al que suscribe de la desaparición de estos grabados”, apostillaba Montalbán. Una posición que, como indicamos, parece apuntar a la estricta necesidad de una defensa preventiva frente a ataques foráneos, y difícilmente por el tenor de lo escrito (pese a que en este caso no se le cita expresamente) podía no estar precisamente Angelo Ghirelli detrás de los mismos. Y ya señalaba Montalbán además la existencia de una cierta proliferación de grabados trazados en los monolitos de Mezora, que nosotros destacamos ampliamente en nuestro trabajo anterior poniendo de relieve una línea no seguida desde antiguo: "de los menhires descubiertos por $\mathrm{mi}$ en las exploraciones del pasado año, hay algunos que tienen incisiones muy particulares". Así pues, se trata obviamente de unos grabados y marcas muy antiguos pues una parte importante de los mismos, que hoy nosotros hemos podido observar, se encontraban hasta la limpieza de Montalbán ocultos por encontrarse enterrados (y por eso no fueron vistos por los visitantes anteriores), y después no han merecido la observación de otros investigadores.

En cualquier caso, la exploración del círculo megalítico permitió a Montalbán detectar el fuerte deterioro que los monolitos habían sufrido en muchos casos. A veces porque fragmentos de los mismos habían sido arrancados en el pasado y se encontraban reutilizados en algunas de las chozas de los alrededores. En otras ocasiones los mismos estaban partidos, de forma sin duda voluntaria e incluso a altura similar, pero los fragmentos pétreos se hallaban en las cercanías. Ello supuso su trabajo de restauración (fig. 4) que, como detectamos para el caso de la entrada al círculo reflejada por los viajeros del siglo XIX, significó el desplazamiento de algunas piezas. Pese a todo, esta labor de Montalbán resultó importante y refleja la agresión a la que en algún momento o momentos fueron objeto los monolitos del círculo. De momento, el establecer la época sería pura especulación. [8]

Por último señalamos un hecho que se mantendrá en la incógnita. En las fotos aéreas de la época de las excavaciones se detecta una especie de recinto de una forma trapezoidal excavado delante de la fachada de entrada que se supone por todos principal del monumento, frente a El Outed o monolito mayor. Podría ser resultado artificial del propio proceso de excavación, pero en su momento Georges Souville, a través de una reconstrucción "photogrammétrique" dedujo que con mucha probabilidad 


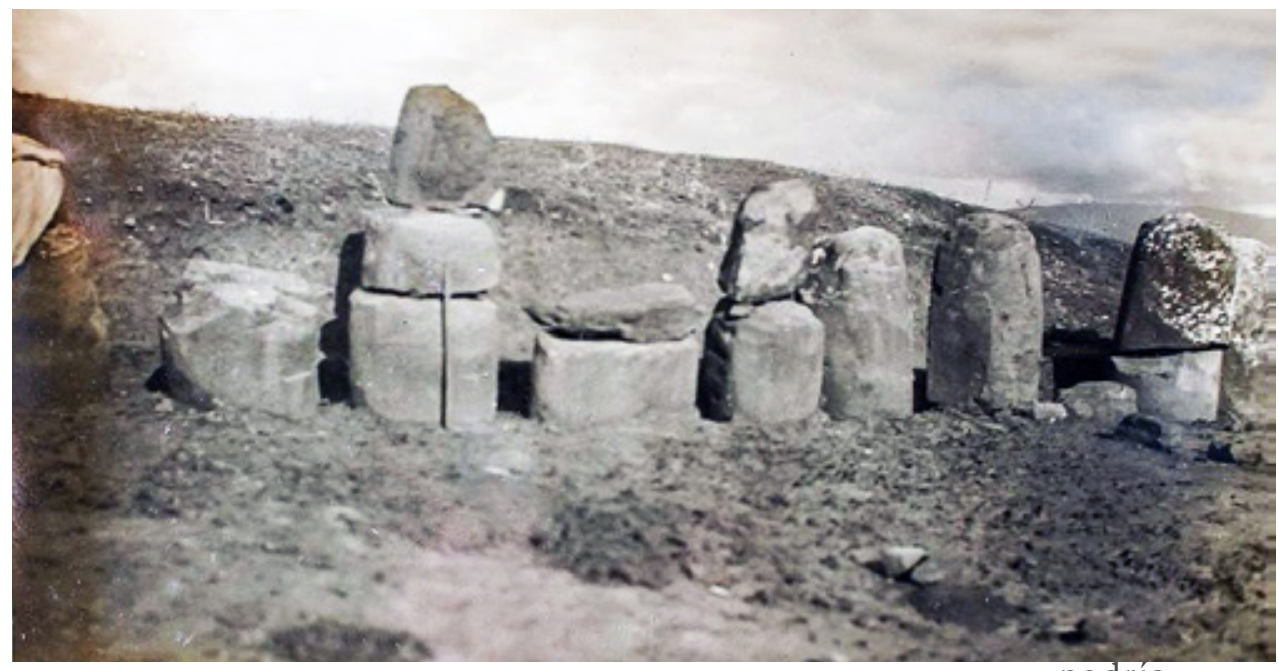

Fig. 8. Monolitos partidos a propósito en el monumento de Mezora.

podría

tratarse de una zona ritual de sacrificios con un altar (Souville, 2000). Nada dice al respecto Montalbán que no es lógico que, de haberlo excavado, no hiciera referencia a esta estructura por lo que en principio debemos dudar de la existencia real de la misma.

\section{Los últimos informes sobre Mezora}

El tercer y cuarto informes de C. L. Montalbán sobre Mezora, que ahora han sido puestos a nuestra disposición como papeles de su archivo, constituyen ya unas visiones que son importantes puesto que son posteriores a esos primeros documentos, por tanto en un momento de mayor avance de los trabajos arqueológicos en el lugar. El tercer informe no tiene una fecha concreta y lleva por título "Exploración del cromlech de M'Zora, poblado de Xuahed”. Sin embargo, la forma del mismo, con la explicación pausada del plan a seguir en la excavación, la referencia de que al estudio de los sílex se dedicará en el futuro el profesor Hugo Obermaier, quien salió de España en el año 1936, la referencia a la "Junta Central" (de Monumentos) que era la denominación específica de la misma en la época republicana, así como el final del propio informe sin tratar expresamente de la parte más central del túmulo, justifica el que atribuyamos al texto una fecha anterior a julio de 1936. Por el contrario, el cuarto informe sí tiene una fecha concreta, la de abril de 1961, la referencia a su redacción en Tánger y el título de "El Cromlech de M'Zora". 
Así pues, con la prevención de que éste último se trata de un escrito nada menos que de un cuarto de siglo posterior a los trabajos, con la más que posible alteración de los recuerdos, aquí si podemos hallar datos relevantes acerca de la visión final del explorador acerca del monumento, tal y como la consideraba en momentos muy tardíos. Y por tanto, recoge unos datos o percepciones que desde la arqueología moderna nos puede permitir un acercamiento a una mejor interpretación del monumento. De hecho, las referencias de César L. Montalbán plantean dudas acerca de algunas de las nuevas conclusiones que hemos comenzado a aceptar en los últimos años, en concreto en lo que se refiere al papel central que en el monumento jugaría la existencia de una tumba que, pese al silencio, el arqueólogo habría explorado.

De hecho, en el texto de 1961 Montalbán habla de la posible existencia de la tumba pero, sin embargo, no recuerda expresamente haber realizado su exploración, contra los testimonios orales que sin embargo hemos aportado más recientemente. El hecho es importante porque afecta directamente a la propia interpretación del monumento de Mezora, como luego señalamos, sembrando bastantes dudas en relación con la posición que adoptemos al respecto. Aclaramos la problemática de forma expresa: la tumba en posición original sería definitiva para interpretar efectivamente el monumento como lo que sin duda fue, un sepulcro monumental, o bien en sentido contrario, el monumento podría interpretarse como un templo solar, una tesis más querida aparentemente por Montalbán.

A partir de algunas consideraciones bastante erróneas, sobre la bibliografía, o sobre la altura misma del túmulo al que atribuye nada menos que 10 metros, es decir cuatro más de la realidad, o bien incluso acerca del número exacto de los megalitos (que considera sólo 117, medio centenar menos de la realidad), con lo que señala la muy evidente alteración del recuerdo sobre el sitio arqueológico, este informe tardío de Montalbán ofrece algunos datos etnográficos que no dejan de ser curiosos, como el hecho de que cuando inició la excavación la parte superior del túmulo estaba allanada puesto que allí se reunían corrientemente los lugareños en actividad social y de charla, así como del hecho de la existencia de las cazoletas o cupules en un conjunto de megalitos exterior, que por las características e indicación del juego tradicional de los niños corresponde con el identificado como grupo A, que es el C de Koehler:

"los menhires que quedan, tienen la particularidad de tener grabadas unas cazoletas que están en la misma posición que las constelaciones que se observan desde el cromlech. Estas cazoletas se encuentran desfigu- 
radas porque los muchachos de las kabilas juegan sobre ellas y su tamaño es veinte veces mayor que las que yo estudié", en referencia a las presentes en monolitos más cercanos. De hecho, ya Tarradell indicó que este importante conjunto de monolitos exterior "fue objeto de una ligera labor de limpieza en las excavaciones de Montalbán” (Tarradell, 1952: 234).

En estos informes de 1936 y 1961 acerca de las excavaciones el arqueólogo volvía acerca de la cuestión de la existencia de un numeroso utillaje en sílex, no sólo en el exterior como hemos visto sino sobre todo recogido en la tierra del interior. Había logrado recopilar en sílex unas 2.000 piezas cuyo destino en 1961 ignoraba totalmente: indudablemente el problema del saqueo de julio de 1936. De hecho, este material se extravío después puesto que no se conserva en el Museo de Tetuán. Consideraba erróneamente que las piezas eran del Paleolítico Medio, y de hecho para mostrar una correcta metodología, consideraba que las mismas fueron recogidas e identificadas por estratos en el túmulo. Naturalmente este hecho no podía dar ningún tipo de resultados que fueran significativos, puesto que como sabemos se trataba de la tierra acumulada para la formación del túmulo. El hecho de que H. Obermaier se fuera a encargar del estudio, como se afirma en el informe número 3, refleja el que en el Protectorado español en esa época se había establecido un mínimo plan de investigación que sería arruinado por la guerra civil (Gozalbes, 2016).

Añade en el informe de 1961 que en la apertura de esta primera zanja, en sentido Oeste-Este hacia el centro del túmulo, partiendo del monolito principal en altura de El-Outed, no dio muestras de ningún resultado. Así pues, aparentemente Montalbán procedió con cuidado y no destrozó ninguna estructura sino que, por el contrario, su excavación mostraba que, contra lo previsto por todos, no había un corredor que diera lugar a la sepultura de Mezora. Se explica así, sin duda, la confirmación de su propia percepción que reflejará en el informe tardío a partir de ese punto: Mezora no constituía realmente una sepultura sino un templo solar megalítico, al estilo del más famoso paralelo británico de Stonehenge en Gales. Sin embargo, en el informe del mismo año 1936 Montalbán había sido mucho más preciso y clarificador en relación con diversos aspectos que nos interesan especialmente. Así hablaba de la presencia en una parte del círculo de un murete de contención de la tierra, con las lajas muy cuidadas (lo que hemos mencionado como el paramento que tiene un clarísimo carácter helenístico). Aquí igualmente mencionaba la existencia por el exterior, junto al círculo de una posible tumba de lajas de piedras en el NE. anexa al círculo sobre la que no sabemos absolutamente nada.

$\mathrm{Y}$ también en este informe de la misma época de la excavación 
Montalbán era mucho más explícito y clarificador sobre el primer corte en sentido Oeste-Este. Entonces mencionaba en el interior la existencia de dos muros concéntricos de piedras, más alto (hasta el doble) el del interior, un hecho sin duda directamente justificado por la propia altura de la colina artificial mayor hacia ese interior. Estas piedras acumuladas para la formación de ambos muros de forma muy clara, al menos a nuestro juicio, eran precisamente el resultado del desbastado de los monolitos del exterior. Volveremos al respecto más adelante, pero la existencia de estos muros de piedra, ignorados en toda la bibliografía tradicional, fue puesta de relieve por nosotros a partir de las fotografía aéreas (Gozalbes, 2006: 336-342), tal y como se ve incluso en la fotografía que reproducimos (fig. 3).

Pero es cierto que otras fotografías del documento de los "Gráficos para el estudio del Cromlech de Mezora" muestran las características de esa acumulación de piedras: en las mismas puede detectarse la existencia de una mayoría de piedras informes, que eran los restos del señalado devastado, pero también la relevante presencia de unas lajas aparentemente bien cortadas, que precisamente muestran el carácter tardío de la construcción del túmulo. [9]

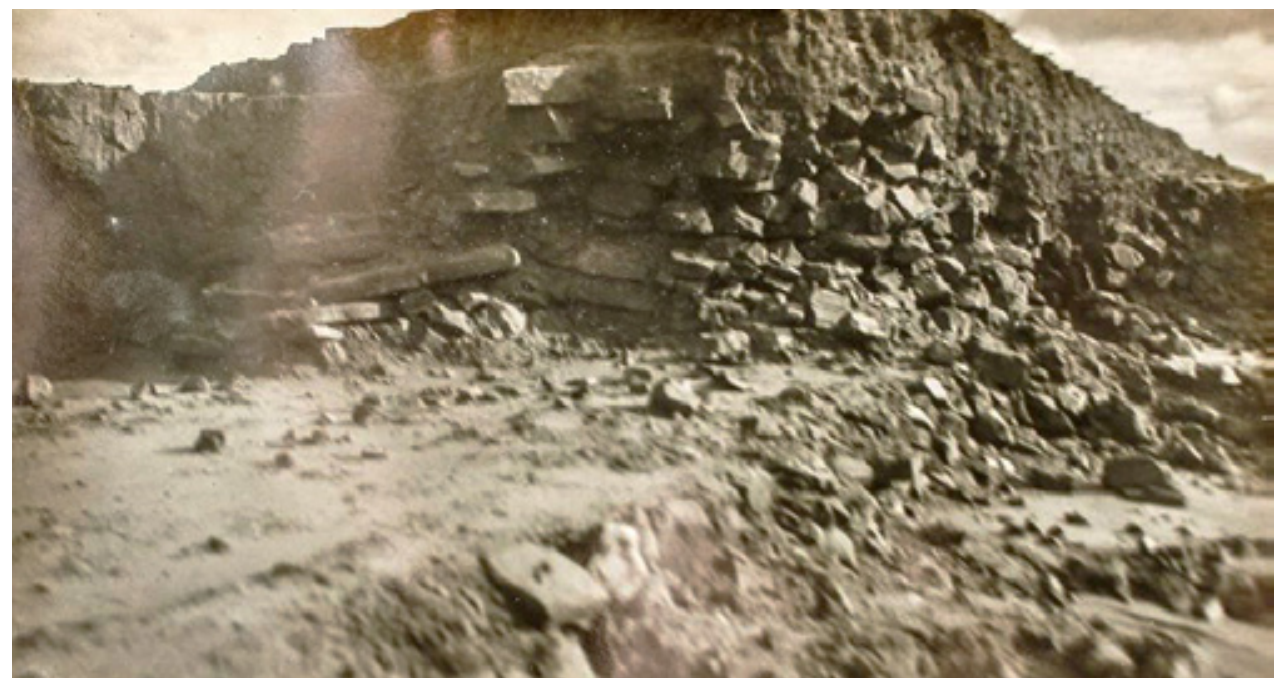

Fig.9. Monolitos partidos a propósito en el monumento de Mezora.

Por otra parte, el tercer informe ofrece un dato muy especial que luego se silenciara de una forma absoluta, como si hubiera sido inexistente, en el cuarto escrito, el del año 1961. Se trata de la existencia de un "túmulo central", que estaría formado por unas piedras más grandes que 
las de los muros, y que claramente apunta a que el monumento originalmente o más tarde en realidad se trataba de una tumba: el propio Montalbán lo llama expresamente con el nombre de túmulo, e indica que tiene base apisonada, con arenas muy finas traídas de unas zonas lejanas, unas señales evidentes de fuego incluidos restos de maderas quemadas, unos molares de bóvido y muy próximo el fragmento de un cuenco de cerámica "neolítica", es decir se entiende que facturada a mano y no a torno. Aquí se encuentra la alusión a la tumba de cremación de otras referencias orales, a la que le falta la referencia al instrumento metálico, también transmitida por la información oral, y por los relatos a otras personas (entre ellas P. Quintero). La particularmente confusa referencia de César L. Montalbán en este caso no elimina la posibilidad de que realmente se tratara de una cista o caja grande de lajas de piedra, siguiendo la tradición de la Edad del Bronce tangerina (lo que se deduce además de las observaciones de P. Quintero) (Quintero, 1941).

En el cuarto informe, el escrito en el año 1961, Montalbán pasaba absolutamente de puntillas en relación con el trazado de la primera zanja. Según él, dado que no encontró nada en la misma, decidió el trazado de otro corte en sentido Norte-Sur. Indicaba que en la misma en un principio no se encontraron diferencias respecto al corte anterior, obviamente se comenzó a abrir desde el exterior, hasta que por el interior se llegó a la zona más próxima a la intersección central. Aquí ya sí se encontró una diferencia que era bien perceptible: hasta ese punto las piezas acumuladas, junto a la tierra, para la formación de esa colina central o túmulo estaban regularmente puestas por capas. Sin embargo al llegar a esta zona central desde el Norte, por el contrario se podía detectar que las piedras estaban acumuladas no por capas sino sin orden ni concierto. Una observación interesante ahora señalada es que las mismas correspondían a tres tipos de piedras distintas, procedentes de unas canteras diversas, lo que parece indicar claramente que estas piedras acumuladas para la formación de la colina constituían los restos del desbastado de los monolitos trabajados del círculo. Este hecho apunta con una mayor verosimilitud, aunque ciertamente no total seguridad, a que la construcción del túmulo o colina artificial del interior es contemporánea, o cuando no muy poco posterior, a la del propio círculo exterior de megalitos, puesto que aquí se reaprovecharon los detritos de la fabricación del mismo.

Otro aspecto particularmente interesante es el que seguidamente se recoge. A la luz del mismo, o nos hallamos ante lo que parecer constituir un auténtico delirio de fantasía por parte del autor, excepto que Montalbán ciertamente hubiera hallado correctamente las evidencias, que no 
explicita suficientemente, de una construcción inicial de un culto de tipo solar mucho más que de una sepultura. Se trata, por tanto, de una fuerte contradicción con lo escrito en junio-julio de 1936 y que afecta muy directamente al fondo de la interpretación del monumento de Mezora. Debido a la naturaleza de las propias expresiones nos parece imprescindible en este caso recoger las propias palabras de Montalbán para poder desarrollar acerca de las mismas las necesarias interpretaciones:

Cuando habíamos pasado dos metros del centro del túmulo, nos encontramos con la clave del mismo; éste consistía en una serie de taulas y trilitos (la taula es una loza sin formatizar sostenida por una sola piedra. El trilito es casi siempre una loza formatizada sostenida por dos pies también formatizados, ambas sirven como mesas para los sacrificios) colocados unos sobre otros que marcaban las diferentes capas de piedras que forman el túmulo. De este interesante punto se sacaron unas fotografías que son documentos gráficos de la formación del túmulo. Examinadas las taulas y trilitos, pude observar que las más próximas al suelo eran taulas y las de la parte superior eran trilitos, siendo las taulas lozas son formatizar y los trilitos estaban formatizados. Fueron retirados las taulas y trilitos y colocados en la parte Este del corte Este- Oeste y de esta colocación se sacaron unas fotografías en las que se ven cuatro taulas y tres trilitos, más un trozo de roca que mirado de perfil se podría tomar como la estatua de una mujer semejante a la que vemos en la obra de Obermaier. Cuando quedó libre el punto sobre el que estaban las taulas y trilitos quedó al descubierto un pequeño círculo con marcado con piedras sin formatizar que representaba al Sol y sobre el que se hicieron todas las ceremonias del culto solar que dió origen al cromlech. Cuando llegué a este punto estábamos en el 17 de Julio del año 1936 fecha en que cesaron mis exploraciones en el cromlech de M'zora.

Los datos parecen señalar la existencia en la zona central del túmulo de unos conjuntos de monolitos en formación, constituidos por los llamados dólmenes, de ellos una parte con un simple pie y que serían más bastos, y otros más cuidados con dos pies y con las lajas mejor trabajadas. Y la alusión a la curiosa piedra con posible forma de perfil femenina que se intuye también en una fotografía. Pese a no haberlo mencionado en el informe de 1936, resulta muy difícil considerar que todo ello simplemente forma parte de la imaginación del arqueólogo, de hecho nosotros no lo creemos así: esas estructuras estaban allí. De hecho, en su álbum de fotografías en los "Gráficos" creemos ver confirmado lo que en 1961 decía de la existencia de "taulas" y "trilitos", así como de la hipotética estatua femenina. La misma representa los restos desplazados y puestos en ex- 
posición en el interior del propio monumento. [10]

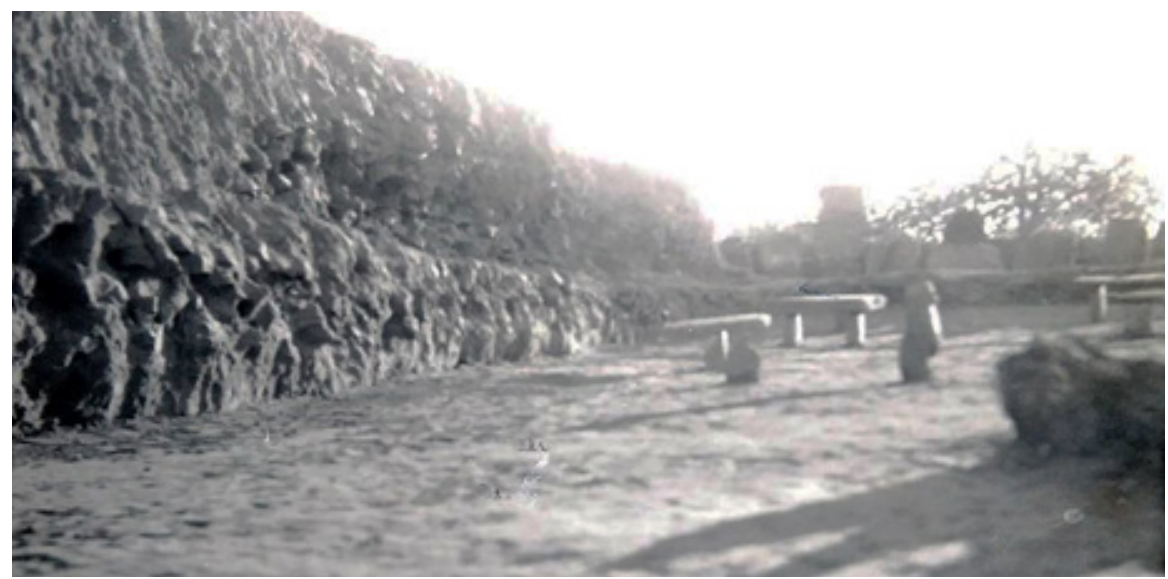

Fig.10. Exposición de piedras de dólmenes e hipotética estatua femenina.

Junto a ello, la existencia del círculo de piedras informes al que se alude y que interpretaba por él como el punto original del monumento para la realización del culto solar. En cualquier caso debe indicarse que los círculos de piedra son relativamente frecuentes en el Norte de África generalmente en relación con tumbas. Pero también hay otros círculos sin relación aparente con tumbas, interpretados de formas diferentes pero entre ellas la de espacios de sacrificio de época protohistórica (Souville, 1964). Así pues, a partir del testimonio de Montalbán sobre las excavaciones, los datos parecen reflejar la posible existencia en el lugar de un espacio ritual inicial, al que pertenecería la piedra que groseramente representaba a

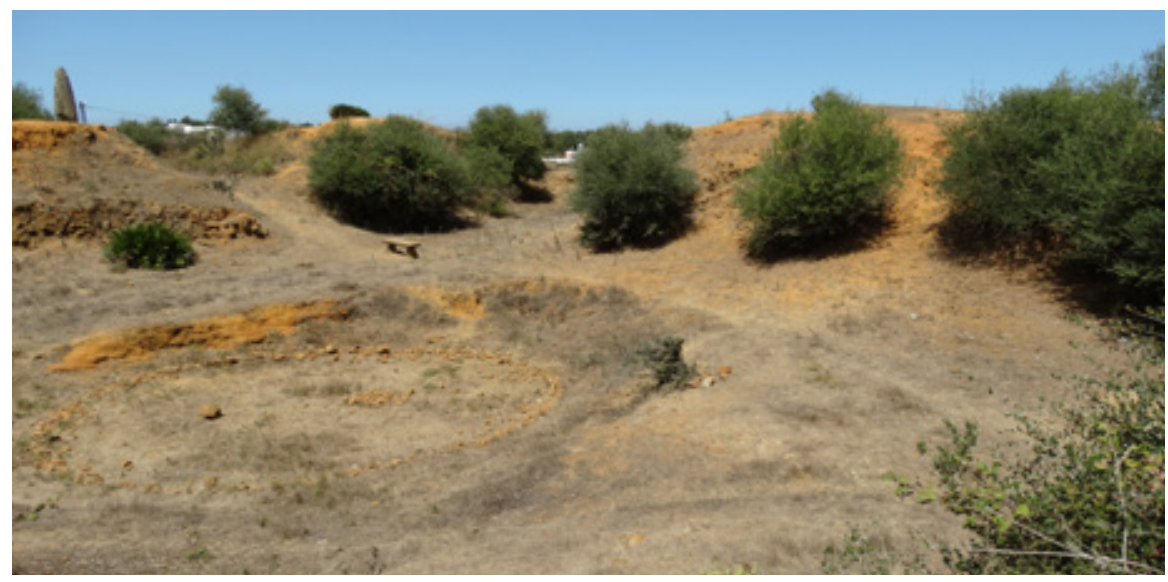

Fig.11. Depresión central en el túmulo de Mezora, muy verosímil lugar de la tumba 
una fémina, y que se transformó con inmediata posterioridad con el túmulo que tendría ya una función funeraria. El lugar de la tumba que Montalbán prácticamente no describe muy probablemente coincide con la gran depresión de la zona central que prácticamente todos los años se inunda con la lluvia. [11]

\section{Conclusiones}

Los documentos elaborados por C. L. Montalbán entre 1934 y 1961 constituyen una fuente importante para conocer el proceso de excavaciones y los resultados en el monumento. Con su aporte documental pueden resolverse algunas dudas y también se focalizan más algunas de ellas que se suscitan, siempre que tengamos en cuenta la diferencia en el estilo de un informe arqueológico actual y otro de la época.

-Como nosotros señalamos por vez primera en nuestro trabajo de 2006, en el interior del monumento (a través de las fotos aéreas) se detectaba la existencia de piedras y estructuras constructivas. Los informes de Montalbán no sólo lo confirman, sino que hablan de otras sencillas estructuras ("trilitos" y "taulas") que a raíz de la propia excavación él reconstruyó en exposición para futuros visitantes (de hecho, el arreglo probablemente se realizó con motivo de la visita del Jalifa del Protectorado a los trabajos desarrollados). En cualquier caso, basta con ver que se trata de piedras bien cortadas para señalar que no nos encontramos ante restos neolíticos sino de la prehistoria reciente. [12]

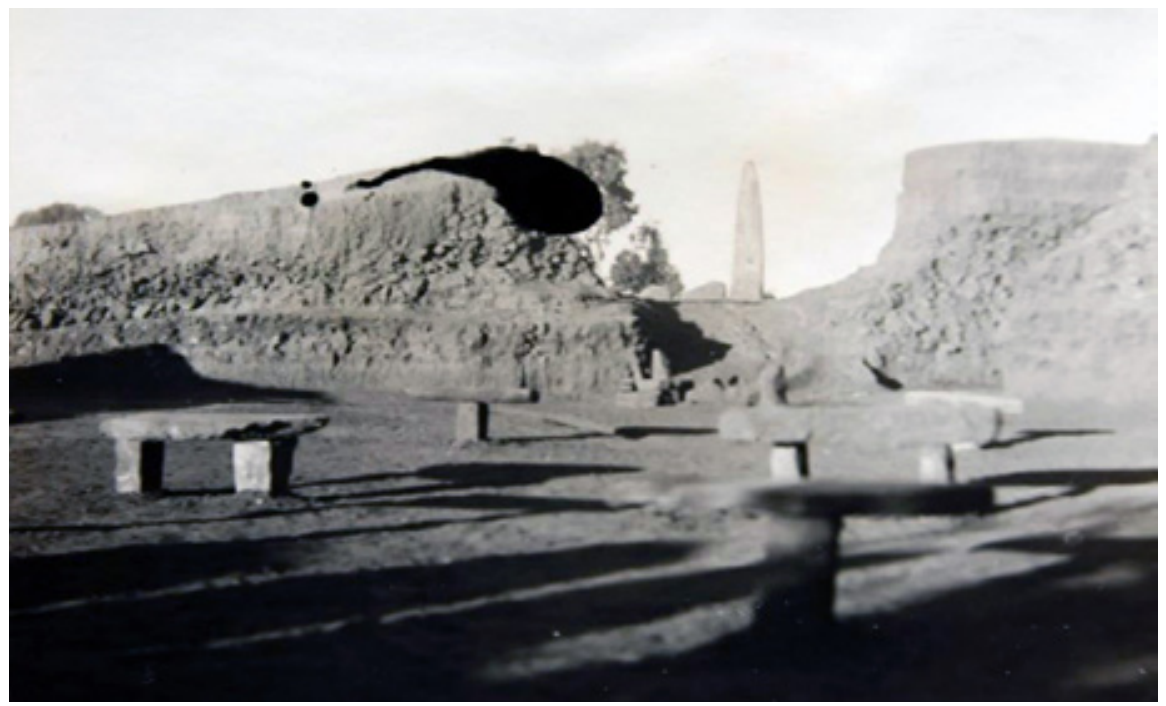

Fig.12. Exposición realizada por Montalbán de estructuras megaliticas internas. 
- Sobre la construcción del monumento, de hacer caso a los datos recogidos en los escritos podría deducirse la existencia de una fase inicial de existencia en el lugar de un espacio ritual, reconvertido con posterioridad ya en un sepulcro monumental. La percepción de Montalbán acerca del interior apunta a lo primero, más allá de lo que parece ser el papel central del Sol al respecto (en lo cual indudablemente insistirá la arqueoastronomía).

- A partir de aquí queda planteada la evidente duda de la relación con el propio círculo de megalitos del exterior, que pudo construirse inicialmente o con posterioridad al espacio ritual.

- En cualquier caso debe indicarse que no medió mucho tiempo entre el espacio ritual y su rápida transformación en tumba.

- Todos los datos parecen apuntar no propiamente a que nos encontramos ante un espacio "prehistórico", pese a las apariencias externas del círculo de megalitos, sino a una época protohistórica, en el primer milenio a. C., y en concreto a partir de mediados del mismo, como muestran las piedras bien cortadas, el aparejo helenístico, así como el uso del rito de la cremación.

De hecho, aunque se ha distinguido en alguna ocasión entre el círculo megalítico y el túmulo, a nuestro juicio uno está hecho directamente en función del otro. El enlosado del pasillo interior, con piedras perfectamente cortadas de cantera, marca esa simetría con el círculo y, de hecho, hay monolitos que descansan o se sostienen sobre las piedras del enlosado. En este sentido, más allá de ese círculo de piedras, de esos llamados "trilitos" y diversas "taulas" del interior, todo apunta a una construcción en la que incluso se utilizó el hierro para realizar el trabajo. Como señalamos, las piedras de algunas de esas estructuras aparecen muy bien cortadas, como se presenta también en el aparejo de tipo helenístico de alguna zona del muro de contención de la tierra.

En suma, el poder disponer de los informes de Montalbán, a cuya familia agradecemos encarecidamente el haberlos puesto a disposición y autorizar su uso científico, aclara algunos puntos, abre nuevas perspectivas, aunque mantiene también naturalmente algunas incógnitas. En principio concluimos que se trató de un espacio de culto, probablemente (pero no seguro) con contenidos de carácter solar y de fecundidad (estatua femenina), pero que muy rápidamente se reconvirtió en una tumba monumental, dotada de un espectacular círculo de megalitos y enlosado, que con toda probabilidad perteneció a uno de los reyes iniciales del reino de la Mauretania, considerado el legendario Anteo por los mauritanos con posterioridad. 
Plutarco (Sert., 9) narraba que durante su actuación en la región de Tingi (Tánger) el general romano Sertorio habría decidido abrir la tumba que se le enseñaba, como si fuera la tumba de Anteo, para descubrir lo que había en su interior, y según se contaba, efectivamente, encontró en su interior los huesos de un personaje de unas grandes dimensiones, ante lo cual decidió volver a cerrar la tumba entre grandes reconocimientos y honores religiosos. La medida atribuida para el sepultado de unos 60 codos, es decir 26 metros de longitud. Por su parte el historiador latino Tausio Gémino (en Estrabon XVII, 3, 8) señalaba que cerca de Lynx existe la sepultura de Anteo, con un esqueleto de sesenta codos, que fue desenterrado por Sertorio y vuelto a inhumar de nuevo. Por su parte Plinio (NH. V, 3) no mencionaba la tumba pero sí Lixus como lugar del combate entre Hércules y Anteo que dio muerte a este último (Gozalbes, 2010). La existencia de una gran tumba monumental en la región no desentona en absoluto con su localización en Mezora. Al menos en esta atribución del monumento de Mezora con la tumba explorada por el general romano Sertorio estamos de acuerdo prácticamente todos los investigadores desde que lo planteó en su día M. Tarradell.

\section{Anexo}

Como hemos señalado, el proyecto arqueológico de Mezora fue el principal que afrontó el Protectorado español en época de la Segunda República, después de la nueva "inauguración" (la segunda) del Museo Arqueológico de Tetuán en noviembre de 1931. Dada la pugna inicial por el mismo, y los problemas políticos del propio régimen, no es nada extraño que pasara por vicisitudes que apenas nos son conocidas, en la relación entre política y conocimiento científico. El régimen franquista utilizaría precisamente tiempo después la investigación arqueológica como uno de los puntales de la que llamó en cultura "hermandad hispano-marroquí". Lo cierto es que problemas económicos, desde luego, pero también con toda probabilidad políticos, condujeron a que los trabajos de Mezora quedaran suspendidos en 1935. No tiene nada de extraño ni lo primero ni lo segundo, tengamos también en cuenta los constantes cambios de gobiernos dentro de la derecha política entre 1934 y 1936. Pese a todo, el episodio que recogemos se produjo en una etapa de cierta estabilidad en el mando español en Marruecos, bajo Manuel Rico Avelló (enero de 1934 a enero de 1936) como Alto Comisario.

Se trata de la ya mencionada visita al conjunto de Mezora por parte del Jalifa de la zona cherifiana, el príncipe Muley el-Mehdi (1915-1984). Se trataba de la segunda visita de un Jalifa a un campo arqueológico, pues 
su padre ya había realizado su primera salida del palacio en 1922 para ver las excavaciones de la ciudad mauritano-romana de Tamuda, junto a Tetuán. En este caso, el Jalifa contaba con 20 años, llevaba ya muchos en su puesto por el fallecimiento de su padre. Y en concreto la visita a Mezora se produjo el 26 de septiembre de 1935.

De la visita hemos logrado reconocer algunas fotografías, de muy mala calidad en la reproducción. Y también de una noticia aparecida en el diario ABC del 27 de septiembre de 1935. En ella se informa de que el Jalifa había visitado el día anterior Mezora en compañía de D. Emilio Tubau, Secretario de la Junta Central de Monumentos Históricos de Marruecos. Se trata de Emilio Álvarez Sanz-Tubau, un personaje miembro del cuerpo de intérpretes de Árabe del Protectorado, y que durante estos años (y más aún bajo la Segunda República) se convirtió en el verdadero alma de la organización de la Junta Superior. Realmente no publicó nada de arqueología, pero sí estaba muy al tanto de la misma pues recibió a los investigadores franceses (Carcopino, Thouvenot) que querían ver los materiales del Museo Arqueológico de Tetuán. "Tubau" (como era generalmente conocido) publicó trabajos de difusión del patrimonio, sobre todo dirigidos al turismo, del cual fue un gran promotor. Se trata sin duda de un personaje que precisa de un estudio en sus aportaciones. Mantuvo una fuerte amistad o al menos confianza con César Luis Montalbán. De hecho, en el archivo de éste, se conserva un documento en varias cuartillas en las que Montalbán recogía datos y deseos para su familia, en relación con su detención por parte de los franquistas ( $\mathrm{y}$ de las negras perspectivas de su propia y cercana eliminación). En ellas prácticamente declaraba a su gran amigo Tubau como albacea testamentario.

Esta visita del Jalifa, en sí misma, se intuye que fue una iniciativa del Secretario de la Junta. Quizás la clave de la misma se encuentra en aquello que recoge la propia noticia, de que los trabajos habían quedado suspendidos por falta de "consignación". No es demasiado imaginativo probablemente el sospechar que la visita era una forma de presión a las autoridades españolas del Protectorado (puesto que no era el propio Alto Comisario el que efectuaba el acto) para que priorizaran la solución del problema. Se indica que en el lugar de Mezora, "donde existían dólmenes y otros monumentos de extraordinario valor arqueológico". Se añade que el Jalifa "escuchó atentamente las explicaciones que le dio el arqueólogo Sr. Montalbán y mostró vivo interés por los trabajos".

En la primera de las fotografías se observa cómo Montalbán, entre los monolitos de Mezora, efectúa sus correspondientes explicaciones al Jalifa que va acompañado de su séquito, formado indudablemente por su 
equipo de delegados, todos ellos con chilaba blanca. También aparecen militares y se adivina un civil, con traje oscuro, indudablemente Emilio Álvarez Sanz-Tubau. En la fotografía número 6 el Jalifa encabeza la comitiva que pasa delante de la entrada principal y más conocida del monumento, en la que se puede observar la gran zanja ya abierta.

\section{Bibliografía}

DAUGAS, J. P., EL IDRISSI, A., DAUGAS, C., CHEVET, P. y OUCHOU, B. (2003) "L'ensemble mégalithique et le tertre funéraire de M'Zora à Chouhed (T'Nin de Sidi L'Yamani, province de Tanger, Maroc)", Origines et développement du mégalihisme de l'Ouest de l'Europe, Bouges, pp. 757-768.

GOZALBES, E. (2006), "El monumento protohistórico de Mezora (Arcila, Marruecos), Archivo de Prehistoria Levantina, 26, pp. 323-348.

GOZALBES, E. (2008), "La arqueología española en Marruecos (19211936): memorias y desmemorias", en MORA, G., PAPÍ, C. y AYARZAGÜENA, M. (Coords.), Documentos inéditos para la Historia de la Arqueología, Madrid, pp. 183-196

GOZALBES, E. (2012), Observaciones sobre el conjunto megalítico de Mezora (Arcila, Marruecos)", Almogaren, 43, pp. 133-154.

GOZALBES, E. (2010), "Los orígenes del reino de Mauretania (Marruecos)", Polis, 22, pp. 119-144.

GOZALBES, E. (2012a), Marruecos y el África occidental en la historiografía y arqueología española, Ceuta, Instituto de Estudios Ceutíes.

GOZALBES, E. (2015), “Arqueología española para un nuevo régimen: Martínez Santa-Olalla y el Norte de Marruecos", Onoba, 3, pp. 3-14.

GOZALBES, E. (2016), "Africanism and international relations in Spanish prehistoric archaeology", en DELLEY, G. Delley, DÍAZ-ANDREU, M. et Alii, History of Archaeology. International perspectives, Oxford, Ed. Archaeopress Archaelogy, pp. 63-70.

GOZALBES, E. (2017), "Relaciones internacionales de la arqueología en el Magreb: la Socièté d'Histoire et d'Archéologie de Tanger ", en 150 años de Historia de la Arqueología. Teoría y método de una disciplina, Madrid, Museo Arqueológico Nacional y Sociedad Española de Historia de la Arqueología, 2017, pp. 815-833.

GOZALBES, E. (2018), Los Apuntes de Prehistoria norte-marroquí de Angelo Ghirelli, Ceuta, Archivo Central.

GOZALBES, E. y GOZALBES GARCÍA, H. (2015-2016), "Nuevos datos sobre el círculo megalítico de Mezora (Marruecos)", Almogaren, 46-47, pp. 55-67.

KOEHLER, H. (1932), "La civilisation mégalithique au Maroc. Menhir de Mçora, Bulletin de la Société Préhistorique Française, 29, 1932, 413-420. 
MARTÍNEZ SANTA-OLALLA., J. (1945), "El africanismo en la Universidad y el Seminario de Historia primitiva del Hombre", África, 46-47, pp. 20-26.

MARTÍNEZ SANTA-OLALLA, J. (1948); IDEM, África en las actividades del Seninario de Historia Primitiva del Hombre, Madrid. 89-121.

MAVOR, J. W. Jr. (1976), “The riddle of Mzorah", Almogaren, 7, pp.

QUINTERO, P. (1941), Apuntes de arqueología mauritana de la Zona española, Tetuán.

PARODI, M. J. (2017), Arqueología e institucionalización del patrimonio en el Norte de África occidental. Pelayo Quintero Atauri, Tesis Doctoral dirigida por RAMOS, J. y BERNAL, D., Universidad de Cádiz..

PARODI, M. J. y GOZALBES, E. (2011), "La arqueología en el Norte de Marruecos (1900-1945)", en BERNAL, D. et Alii (Coords.), Arqueología y turismo en el Círculo del Estrecho, Tetuán-Cádiz, 2011, pp. 175-198.

SOUVILLE, G. (1964), "Note sur un cercle de pierres aux environs de Sidi Harazen (Maroc)”, Bulletin d'Archéologie Marocaine, 5, pp. 315-320.

SOUVILLE, G. (1965), "Élements nouveaux sur les monuments funéraires préislamiques du Maroc”, Bulletin de la Société de Préhistoire Française, 62, pp. 482-493.

SOUVILLE, G. (1968), "Los monumentos funerarios preislámicos de Marruecos. Ensayo de clasificación y distribución”, Ampurias, 30, pp. 39-61.

SOUVILLE, G. (1973), Atlas préhistorique du Maroc. 1. Le Maroc Atlantique, Paris, 1973.

SOUVILLE, G. (2000) Nouvelles observations sur le tumulus de Mezora”, Homenaje al Profesor Carlos Posac Mon, vol. 1, Ceuta, pp. 109-112;

TARRADELL, M. (1952), "El túmulo de Mezora (Marruecos)", Archivo de Prehistoria Levantina, 3, pp. 229-239. 